\title{
POLÍTICAS INDUSTRIAIS VERDES: A INTERPRETAÇÃO INTERNACIONAL E A INSERÇÃO BRASILEIRA DENTRO DO NOVO CONTEXTO DE FORMULAÇÃO DE POLÍTICAS
}

\author{
Danielle de Almeida Mota Soares e José Victor Diogo
}

\begin{abstract}
Resumo:
O presente artigo tem como objetivo fundamental mapear o debate atual a respeito do que se entende por política industrial verde. Para tanto, uma revisão da literatura internacional sobre o tema foi feita com vistas a 1) enquadrar teoricamente os principais conceitos tratados quando se discute políticas industriais verdes e 2) a partir da literatura examinada, lançar luz sobre a recente experiência brasileira na confecção de políticas industriais, mais especificamente com relação à PITCE, à PDP e ao PBM.
\end{abstract}

\begin{abstract}
:
This article's main objective is to map the current debate as to what is meant by green industrial policy. To this end, a review of international literature on the subject was made in order to 1) theoretically frame the main concepts covered when discussing green industrial policies and 2) from the examined literature shed light on recent Brazilian experience in the making of industrial policies more specifically in relation to PITCE, the PDP and the PBM.
\end{abstract}

JEL.: L52; Q00; Q01;

\section{Introdução - a economia ambiental, a ecológica e a verde}

A preocupação com as questões ambientais estão entre os principais temas de pesquisa e formulação de política no mundo todo, desde o final do século passado. Pode-se dizer que isso é resultado de um processo, até certo ponto, ambíguo. Por um lado, a pressão sobre o meio ambiente, poluição de solo, ar e água, bem como a exploração mais rápida de seus recursos naturais aumentaram muito nos últimos séculos em função do ritmo acelerado de crescimento da economia internacional. Por outro, a pressão na forma de cobrança de atitudes que visem à preservação ambiental também se elevou drasticamente. A conscientização da população e das empresas sobre temas ligados à preservação, sustentabilidade etc. cresce dia a dia e se aprofunda com o desenvolvimento científico, com a modernização dos processos produtivos e, também, com a globalização. Dentro da ciência econômica, existem duas correntes de pensamento que se destacam ao contrapor ideias a respeito do tema, de um lado a economia ambiental e, de outro, a economia ecológica.

Em linhas gerais, a economia ambiental é herdeira dos preceitos daquilo que é conhecido na teoria econômica como "corrente principal” ou da tradição da economia ortodoxa. Um de seus argumentos mais fortes, sugerido por Solow (1974), é o de que o limite para o crescimento da economia não está na disponibilidade de recursos naturais escassos, mas, sim, na capacidade de substituí-los trazida pelo desenvolvimento tecnológico. Em outras palavras, quanto mais tecnologicamente avançada for uma economia, mais ela será capaz de tornar a produção mais eficiente em termos de uso de recursos e gasto de energia, a ponto de 
que a escassez dos recursos não se configure em empecilho para o processo de crescimento. Vale ressaltar que, ao indicar essa relação entre desenvolvimento tecnológico e estoque de recursos naturais, Solow (1974) considera que o valor de tais recursos não se difere daqueles produzidos pelo homem, e, dessa forma, ambos podem ser valorados no mesmo sistema de preços no mercado. Dito isso, na visão de Solow (1974), existe um ponto “ótimo" de utilização, e esse ponto é justamente aquele que representa a taxa de crescimento tecnológico. O maior erro, de acordo com Solow (1974), é supor um ponto ótimo que inclui um estoque do recurso, quando o correto seria considerar um ponto ótimo que inclui exaurir os recursos. Outra concepção importante da economia ambiental, ligada à proposta por Solow (1974) é a curva de Kuznets ambiental (CKA) defendida por Grossman e Krueger (1995).

\section{Gráfico 1: Curva de Kuznets}

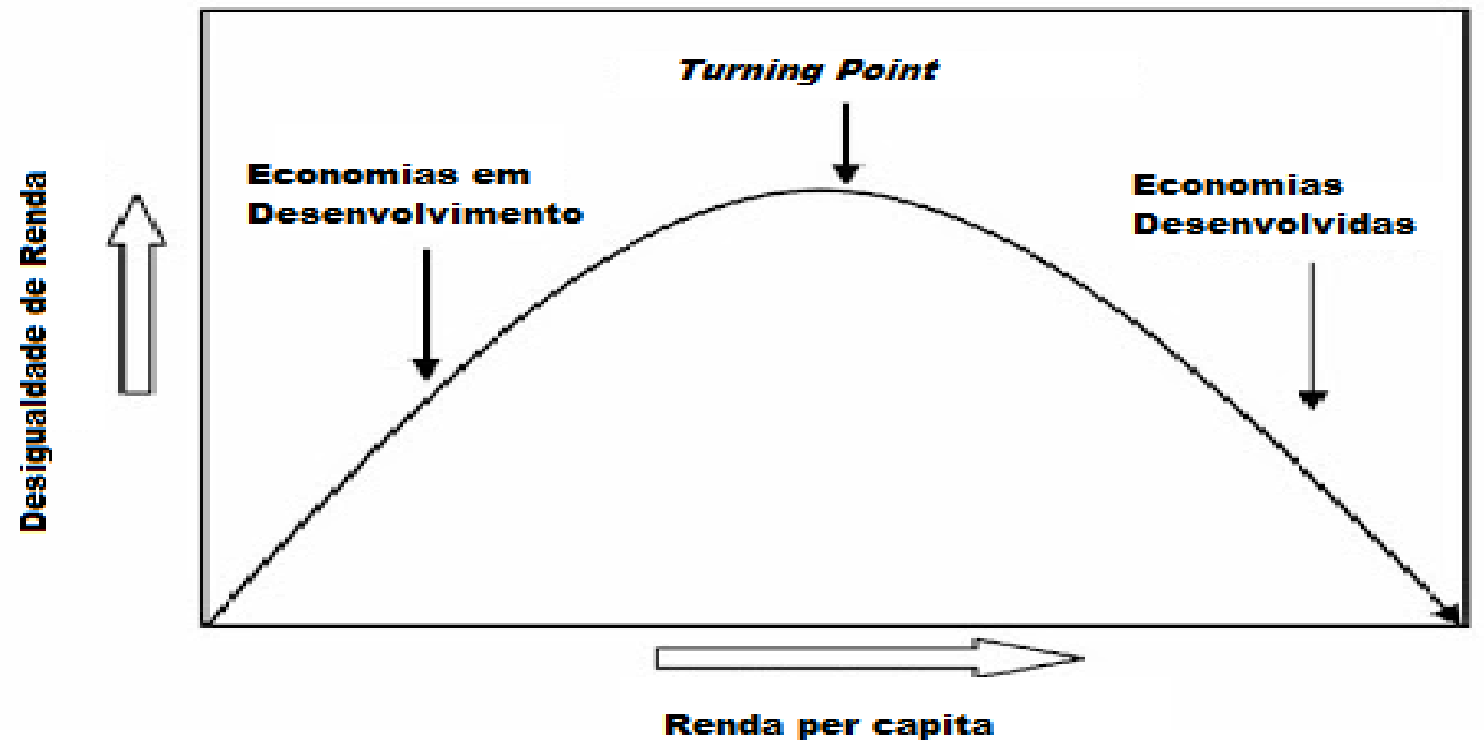

Elaboração própria a partir de informações contidas em Grossman e Kruger (1995).

Esta curva, inspirada na curva de Kuznets original ${ }^{1}$, relaciona a degradação ambiental e o aumento de renda per capita. De acordo com essa construção, países de renda baixa tendem a degradar muito o meio ambiente. No entanto, conforme esses países se desenvolvem, passam a degradar cada vez menos. Seu destaque é justificado por supor que as questões ambientais devam ceder espaço ao crescimento econômico haja vista que depois do pico de degradação ambiental, o turning point, o aumento de renda ocasionaria um decrescimento da degradação.

A economia ecológica, vertente considerada heterodoxa, parte do conceito fundamental de que os recursos presentes no ambiente são finitos. A partir disso, a ideia central é compreender, através de uma abordagem transdisciplinar que integra elementos e estudos de outras áreas científicas, para encontrar os reais mecanismos e impactos da degradação ambiental. Um exemplo claro dessa transdisciplinaridade é a introdução, feita por Georgescu-Roegen (1973), do conceito entropia dentro do contexto econômico. Para o autor, os processos produtivos, ao transformarem a matéria-prima (baixa entropia) em produto final (alta entropia), alteram seu estado energético, com a utilização de materiais finitos e lançamento de resíduos cumulativos no meio ambiente. Além disso, a economia ecológica

\footnotetext{
${ }^{1}$ Desenvolvida por Simon Kuznets, em 1955, a curva em formato de U invertido relaciona a concentração de renda e o crescimento econômico.
} 
questiona a capacidade tecnológica de substituir os recursos naturais. Ao usar o exemplo da indústria mineradora, Georgescu-Roegen (1973), aponta que o progresso tecnológico desse setor veio seguido de uma expansão na exploração de minério, ao baratear seu processo produtivo. Esse argumento vai de encontro ao sugerido pela economia ambiental.

Por fim, é importante ressaltar a Iniciativa Economia Verde, que não se situa em nenhuma das vertentes anteriores, pois se trata de uma proposta de reforma estrutural. $\mathrm{O}$ relatório da UNEP (2011) define Economia Verde como a transição para uma economia de baixo carbono, almejando desenvolvimento sustentável em conjunto com o fim da pobreza. De acordo com a Economia Verde, um dos instrumentos para diminuir as taxas de carbono é o desenvolvimento de tecnologias inovadoras. O funcionamento desses instrumentos exige investimentos em áreas estratégicas sendo elas: agricultura, construção civil, setor energético, pesca, silvicultura, indústria, turismo, transportes, gestão de resíduos e água (UNEP, 2011).

O presente artigo pretende focar em uma das áreas consideras estratégicas pela Economia Verde: a indústria. Mais especificamente, o objetivo fundamental é o de inserir, dentro do debate exposto até aqui, a questão da política industrial, tanto no âmbito brasileiro, como no âmbito internacional. Para isso, além dessa introdução e da conclusão, a seção 2 apresenta uma revisão da literatura sobre política industrial verde. A seção 3 discute, mais detidamente, quais os instrumentos utilizados pelas últimas três políticas industriais brasileiras que tenham alguma relação com a montagem de instrumentos de política verde.

\section{Enquadramentos teóricos encontrados na literatura internacional - em busca de uma política industrial verde}

As preocupações reveladas por grande parte da literatura internacional coincidem com as encontradas no Brasil em relação aos conceitos e teses clássicas sobre política industrial. Contudo, quando inserida a questão ecológica, percebe-se claramente que, internacionalmente, a discussão já se encontra adiantada em diversos pontos. É clara a percepção de que o mercado, enquanto instituição autossuficiente e autorregulada, não tem condições de internalizar, através de seus sistemas de preços, as externalidades oriundas do uso de recursos naturais e do descarte de rejeitos e excedentes que poluem o meio ambiente. Dessa forma, algum intervencionismo estatal se mostra necessário, especialmente na composição de políticas industriais, naquilo que ficou conhecido na literatura como second best choice $^{2}$ (SCHWARZER, 2013; COSBEY, 2013; RODRIK, 2014; LÜTKENHORST E PEGELS, 2014). Um exemplo disso está em Altenburg (2011) ao registrar que o ditame de grande parte das políticas industriais convencionais concentrava-se no aumento da produtividade do trabalho e do capital no setor privado em concomitância com uma redução gradual do chamado intervencionismo estatal. No entanto, em função da nova agenda ecológica de prioridades que visa acelerar o processo de transformação do setor industrial para um paradigma mais correto do ponto de vista ecológico, o ritmo de inovação tecnológica tem que ser acelerado e isso, por sua vez, só é possível via instrumentos de ação do próprio Estado. O autor vai além ao propor que:

Dadas as drásticas consequências esperadas da mudança climática e o aumento da deterioração de outros recursos ambientais, o desenvolvimento de tecnologias recurso-eficientes é provavelmente o desafio mais importante para a política industrial futura. $\mathrm{O}$ debate atual está focado em tecnologias de baixo carbono, mas a

\footnotetext{
${ }^{2}$ Segunda melhor escolha, em tradução livre, referencia uma política alternativa, haja vista que a melhor escolha (best choice) que seria a otimização via uso dos instrumentos de mercado está impossibilitada.
} 
escassez de outros recursos finitos - particularmente água e solo fértil - também se tornará grave em âmbito global.3 (ALTENBURG, 2011, p. 26)

Desta forma, busca-se evidenciar que o que se pensa a respeito do setor industrial está cada vez mais atrelado a uma ideia de desenvolvimento sustentável. De acordo com documento lançado pelas Nações Unidas, o conceito de desenvolvimento sustentável é amplo e vem sendo lapidado no decorrer das últimas duas décadas. Apesar disso, existem três pilares fundamentais sobre os quais ele deve ser sustentado, sendo eles: desenvolvimento econômico, equidade social e proteção ao meio ambiente (ONU, 2010).

Na literatura internacional já são consideráveis as diversas tentativas de se promover uma demarcação clara do que se entende por uma política industrial que cubra os três pilares citados, em especial, a atenção às questões ambientais. A essa política vem sendo dada a alcunha de política industrial verde.

\subsection{Política Industrial Verde}

Em meio à abundância de definições e concepções para política industrial verde, é válido o empenho em garimpar quais aquelas que auxiliariam, de fato, na montagem de um enquadramento teórico para o entendimento amplo do tema.

\subsection{1 - O conceito}

A amplitude do conceito é uma característica importante uma vez que, neste trabalho, pretende-se compreender de forma mais geral os impactos da criação e implantação de uma política industrial verde, em todos os âmbitos da economia. Parte da amplitude citada é explicada por Hallegate, Fay e Schlib (2013). As autoras argumentam que a política industrial verde deveria ser entendida, literalmente, como a união de todas as prerrogativas de uma política ambiental (ou política verde) com aquelas de uma política industrial. Isso faz com que se crie uma distinção automática entre instrumentos e objetivos de demanda e instrumentos e objetivos de oferta. Se uma política visa recompensar o consumo (demanda) de um bem verde, por exemplo, de algum biocombustível, sem dar conta dos meios de produção ou de importação/exportação (oferta) desse bem, pode-se dizer que essa política é verde, sem, contudo, ser industrial.

Dito isso, entende-se que a definição mais completa é aquela dada por Pegels (2014, p. 7): "intervenção governamental para acelerar a reestruturação da economia em direção à sustentabilidade ambiental”.

Para introdução desta nova forma de política, é interessante caracterizar dois termos importantes para sua construção sendo eles: indústria verde e esverdeamento industrial, ambos retirados de Schwarzer (2013) ${ }^{4}$. Para o autor, o esverdeamento industrial se refere ao melhoramento constante de todos os setores da indústria a partir da busca de maior eficiência na utilização dos recursos. Este processo está intimamente relacionado com o resource decoupling $^{5}$ relativo observado para a economia mundial nas últimas três décadas. Já a indústria verde faz menção ao desenvolvimento e criação daquelas indústrias produtoras de

\footnotetext{
3 Tradução nossa.

${ }^{4}$ Do inglês original: Green industry e greening of industry.

${ }^{5}$ Resource decoupling ou desacoplamento de recursos, de acordo com o PNUMA, é a redução da taxa de uso de recursos por unidade do Produto Interno Bruto (PIB). O desacoplamento pode ser relativo, quando a taxa de crescimento do uso de recursos é menor do que a taxa de crescimento do PIB; ou absoluto, quando a taxa de extração de recursos se estabiliza em um dado patamar, ou quando esta cai ao longo do tempo enquanto cresce o PIB
} 
bens e serviços verdes (SCHWARZER, 2013). Segundo Cosbey (2013) bens e serviços verdes podem ser definidos como sendo aqueles que:

...possuam melhor performance ambiental em operação do que seus competidores (ex.: veículos elétricos, equipamentos geradores de energia renovável, biocombustíveis), que adereçam problemas ambientais (tecnologias de remediação ambiental), ou que são produzidos de maneira ambientalmente preferível em relação aos seus competidores (ex.: agricultura orgânica) (COSBEY, 2013, p. 3) ${ }^{6}$

\subsection{2 - Os principais atributos da Política Industrial Verde}

Schwarzer (2013) organiza os atributos das políticas industriais verdes em quatro segmentos, sendo eles: mecanismos de regulação e controle, taxas ambientais, proteção à indústria e, por fim, apoio à indústria. Os mecanismos de regulação e controle representam imposições sobre o uso de determinadas tecnologias (i.e. proibição de certo tipo de maquinário antiquado muito poluente) e/ou sobre níveis de desempenho ambiental das empresas (i.e. limitar o nível de emissão de $\mathrm{CO}_{2}$ por planta). Esse tipo de ação se mostra cada vez mais comum tanto em países em desenvolvimento como nos já desenvolvidos, apesar das dificuldades encontradas no desenho preciso dos mecanismos.

As taxas ambientais têm, por natureza, efeito duplo. De um lado, ajudam a reduzir a emissão de poluentes via cobrança de alíquotas e, consequentemente, criam vantagens para as firmas que abaterem. De outro, se bem implantadas, as taxas também servem como fontes alternativas de recursos fiscais para o Estado. Schwarzer (2013) afirma que essa opção é mais utilizada em países desenvolvidos em função do receio de impactos negativos na competitividade da indústria nos países em desenvolvimento.

O terceiro segmento citado por Schwarzer (2013) é a proteção à indústria verde. O autor chama a atenção para o aspecto conflitante desse tipo de ação dentro da literatura. Um dos posicionamentos é o da Organização Mundial do Comércio (OMC) em defesa do livre comércio, inclusive para transferência de bens, serviços e tecnologias verdes. ${ }^{7} \mathrm{Wu}$ e Salzman (2014) analisam os casos de disputas da OMC os quais denominam Nova Geração, que compreende questões relativas aos subsídios governamentais à produção de energias renováveis e às restrições à importação de certos minérios cuja extração danifica o meioambiente. Nas palavras dos próprios autores:

Em um mundo no qual as negociações sobre mudanças climáticas são hesitantes e um acordo parece uma esperança distante, política industrial verde tem emergido como uma das mais importantes áreas para progresso real. O debate dessa nova classe de disputas comerciais e ambientais e as regras que moldam a corrida em direção ao futuro da energia renovável tem se tornado uma parte importante da agenda sobre o clima global. A forma como essas regras serão determinadas será crucial para projetar o caminho rumo a um futuro sustentável. ${ }^{8}$ (WU; SALZMAN, p. 474).

Por fim, Schwarzer (2013) destaca o apoio à indústria como importante segmento dentro das chamadas políticas industriais verdes. O problema, evidentemente, parece estar na escolha das indústrias “campeãs” dentro dessa lógica e, mais do que isso, na capacidade de

\footnotetext{
${ }^{6}$ Tradução nossa.

${ }^{7}$ Vide, por exemplo, “Em defesa da Globalização: como a globalização está ajudando ricos e pobres” de Jagdish Bhagwati (2009).

${ }^{8}$ Tradução nossa.
} 
retirar os benefícios daquelas que vierem, por ventura, a ser equivocadamente escolhidas como campeãs.

Rodrik (2014) chama a atenção para três características importantes que as políticas industriais devem ter. A primeira delas é o que o autor chama de enraizamento (embededdness). Segundo Rodrik (2014), a maioria dos países que adota algum tipo de política industrial escolhe, como padrão de gestão, o modelo agente-principal. Neste modelo impera a assimetria de informação uma vez que o agente (firma) sempre mantém ocultos das vistas do principal (agência reguladora) alguns elementos muito relevantes, como, por exemplo, seus custos de produção. O enraizamento, por sua feita, preconiza que a relação entre a burocracia e as empresas que atuam no mercado se dê de maneira mais próxima, permitindo ampla troca de informações e reduzindo ao máximo a incerteza que, especialmente nos setores que compõem a economia verde, é altíssima (RODRIK, 2014).

A segunda característica de uma boa política industrial verde, segundo Rodrik (2014), deve ser a disciplina. Essa proposta, colocada de maneira simples, significa que a burocracia, que gerencia a política industrial verde, deva possuir mecanismos que consigam disciplinar as firmas agraciadas por incentivos e auxílios de qualquer sorte. Para tanto, os objetivos das políticas devem ser os mais claros possíveis e, evidentemente, os métodos de quantificação e avaliação de resultados também (RODRIK, 2014).

Por fim, a terceira característica fundamental colocada por Rodrik (2014) é a prestação de contas (accountability). Como o próprio nome já indica, a prestação de contas é o resultado do enraizamento e da disciplina e está intimamente ligada à ideia cada vez mais difundida de transparência. Vale notar que a prestação de contas deve ser exigência tanto para as firmas que lograram estar no foco das políticas, bem como para o próprio órgão do Estado que exercer o papel de principal.

2.1.3 - A dicotomia entre países desenvolvidos e países em desenvolvimento com relação à Política Industrial Verde

A discussão sobre políticas industriais verdes é usualmente dividida entre duas perspectivas distintas, aquela dos países desenvolvidos e aquela dos países ainda em desenvolvimento. Essa distinção é adotada, primordialmente, em função das diferenças de capacitação tecnológica entre os entes que compõem ambos os grupos, diferença essa que permite ao primeiro grupo adotar medidas mais facilmente, ou, pelo menos, com menor resistência em comparação com o segundo. Sabe-se, por exemplo, que a presença de indústrias verdes está concentrada em países de alta renda (DUTZ; SHARMA, 2012). Além disso, outro problema que restringe a efetividade de políticas industriais verdes nos países em desenvolvimento é a necessidade de crescer no curto prazo. Alguns dos instrumentos deste tipo de política podem ser interpretados como ameaças à competitividade da indústria doméstica, além de afetar a distribuição da renda como, por exemplo, no caso da taxação de um combustível fóssil (SCHWARZER, 2013).

Mesmo sendo válidas as dificuldades enfrentadas pelos países em desenvolvimento, parte-se aqui da ideia de que as políticas industriais verdes podem servir de oportunidade para incremento do dinamismo de suas economias (MARTINEZ-FERNANDEZ ET AL., 2013; SCHWARZER, 2013; HALLEGATE, FAY, SCHILB, 2013).

Para Altenburg (2011), a mudança de postura dos países em desenvolvimento face à emergência de uma economia globalizada, cada vez mais preocupada com os impactos ao meio ambiente e com o desenvolvimento sustentável, é imperativa. Segundo o autor, duas 
seriam as razões para tal. A primeira delas é o conjunto de restrições impostas por parte dos países desenvolvidos, especialmente europeus, sobre a origem de suas importações. Nas palavras do autor, os países em desenvolvimento:

Para assegurar que seus produtos sejam exportáveis, é importante construir um
sistema de produção eficiente e ambientalmente sustentável e montar esquemas de
controle de qualidade, o que pode ser complicado uma vez que isso não implica
somente a necessidade de instalação de laboratórios e sistemas de rastreabilidade -
que exportadores comerciais normalmente são capazes de gerenciar - mas também
construir confiança, sensibilizar e treinar pequenos agricultores, dar suporte a ações
coletivas entre os produtores, lançar campanhas para resgatar a confiança dos
consumidores e negociar com as autoridades dos países importadores.
(ALTENBURG, 2011, p. 51) ${ }^{9}$

A segunda razão que torna imperativa a adequação dos países em desenvolvimento às novas restrições ambientais é de ordem interna. Isto porque os efeitos das mudanças climáticas e da escassez de recursos como água e solo, entre outros problemas ambientais, serão sentidos em seus próprios territórios. Mudanças no gerenciamento de recursos, incrementos na produtividade, tanto do trabalho como do capital, treinamento e qualificação de mão de obra, são fenômenos necessários para lidar com as imposições de um mundo orientado para o desenvolvimento sustentável e todas abrem ensejo para a montagem de uma política industrial verde (ALTENBURG, 2011).

Dutz e Sharma (2012) enfatizam a afinidade fundamental que existe entre a geração e promoção do setor de bens e serviços verdes e a inovação. Nos países em desenvolvimento essa relação é, no geral, muito comprometida. Mas, segundo os autores, é possível prover, através de políticas corretas, o surgimento de atividades inovativas impulsionadas por setores verdes.

\begin{abstract}
Novas fronteiras tecnológicas podem ser criadas e comercializadas mesmo em países onde as capacidades tecnológicas médias são relativamente menos sofisticadas, a partir do momento que exista uma ou mais de uma aglomeração de firmas com capacidades tecnológicas suficientes, idealmente tendo o suporte de um sistema de educação superior de alta qualidade - haja vista que o custo-benefício do apoio ao ensino público é suficientemente alto para garantir o gasto de recursos escassos em detrimento de usos alternativos (DUTZ; SHARMA, 2012, p. 16, tradução nossa). ${ }^{10}$
\end{abstract}

Criscuolo e Menon (2014) também apontam para a conexão entre indústria verde capacidade de inovação, mas fazem a ressalva de que "a estabilidade, sustentabilidade e credibilidade das políticas de longo prazo são importantes para assegurar o financiamento de empreendimentos arriscados no setor verde" ${ }^{11}$ e assim evitar que o alcance das políticas se traduza apenas na criação de tarifas feed-in ${ }^{12}$ e de certificados de comércio, como é comum em países em desenvolvimento que já experimentaram alguma vez com políticas do tipo (CRISCUOLO; MENON, 2014, p. 34).

\footnotetext{
9 Tradução nossa.

10 Tradução nossa.

11 Tradução nossa.

12 Tarifas feed-in (feed-in tariffs) são incentivos fiscais na forma de redução tarifária para aquelas firmas, ou setores, que fizerem uso de métodos de produção, insumos, logística de distribuição mais corretas do ponto de vista ambiental.
} 
Com o intuito de aprofundar a noção sobre o tema, é adequada a apresentação de algumas experiências internacionais na implantação de políticas industriais verdes, tanto em países já desenvolvidos como em países em desenvolvimento.

Lütkenhorst e Pegels (2014) examinam o interessante programa de transição energética alemão (Energiewende), que tinha por objetivo central ampliar a participação das chamadas energias renováveis ${ }^{13}$ na matriz energética daquele país. Os autores mostram que, em 2012, as energias renováveis já representavam mais de $22 \%$ do total de consumo de energia na Alemanha. Os esforços de ampliação dessa margem deixam clara a preocupação patente em se distanciar do padrão de combustíveis fósseis, muito também em função de aspectos geopolíticos que caracterizam as relações europeias, especialmente naquilo que tange à dependência do gás e do petróleo russos.

Para o caso chinês, sublinha-se o estudo da UNEP (2013) China's Green Long March, que traz à luz o caso de dos incentivos às políticas específicas do governo para as energias renováveis, para a indústria de cimento e para o que ficou definido como indústria ambiental (environmental industry), compreendendo, entre outras coisas, o setor de bens ambientais (equipamentos e material usado no controle da poluição, tecnologia de tratamento de água e equipamento para monitoração energética); setores que fazem uso racional dos recursos como, por exemplo, a indústria da reciclagem, projetos de reuso de calor industrial desperdiçado, o setor de serviços ambientais e de produtos limpos, como por exemplo, materiais biodegradáveis e lâmpadas fluorescentes (UNEP, 2013). Outro exame interessante de se realizar é o do caso das políticas industriais verdes postas em prática na Índia. Ganesan et al. (2014) mostram que além do foco na disseminação das energias renováveis, as autoridades indianas também mostraram grande preocupação com o nível de emissão de poluentes que seu parque industrial, bem como setores agropecuários e extrativistas, apresentam.

\section{As três últimas políticas industriais brasileiras e a política industrial verde}

No geral, as críticas da literatura brasileira que pesam sobre o desenho e implantação de políticas dessa natureza podem ser agrupadas em blocos definidos. De um lado, a corrente ortodoxa aponta os desequilíbrios de médio e longo prazo que políticas verticalizadas podem trazer para a economia. Um dos exemplos mais claros se encontra em Canêdo-Pinheiro et al. (2007). Neste trabalho os autores apontam que os mentores das políticas industriais brasileiras focam suas atenções nos casos de sucesso de implantação de medidas verticalizadas ocorridos nos países do Leste Asiático, em especial da Coreia do Sul, Japão e Taiwan sem se dar conta de que nestes mesmos locais também haviam sido estimuladas políticas horizontais, quais sejam: combate a inflação, reajustamento fiscal do Estado, investimentos em educação etc., todos eles ausentes na atual configuração econômica recente do País. Almeida (2013) alerta para a baixa ou até inexistente atenção que as políticas industriais recentes vêm dando aos chamados produtos primários, em especial àquelas commodities que logram enorme potencial exportador para a economia brasileira. Rezende (2013) sugere que incentivos à inovação não deveriam ser orientados àqueles setores que inovariam mesmo sem os estímulos de política, como estaria ocorrendo no Brasil, e vai além ao afirmar criticamente que o Banco Nacional de Desenvolvimento Econômico e Social (BNDES) pretere firmas menores em proveito de firmas maiores, elevando a concentração de mercado.

\footnotetext{
${ }^{13}$ São consideradas energias renováveis, segundo a Agência Internacional de Energia (IEA), aquelas derivadas de processos naturais que são constantemente recarregadas, incluindo energia solar, eólica, biomassa, geotérmica, hidráulica, além de biocombustíveis e hidrogênio derivado de fontes renováveis.
} 
A crítica heterodoxa, por sua vez, incide, principalmente, sobre a pouca efetividade das políticas industriais implantadas na geração e difusão de inovação dentro do parque industrial nacional, item essencial quando se trata de competitividade internacional da economia brasileira. De acordo com Melo, Fucidji e Possas (2015, p. 32-33):

...o foco das políticas de ciência, tecnologia e inovação no provimento de recursos para a inovação, a formação de recursos humanos e a pesquisa acadêmica não tem resultado no desenvolvimento de capacitações tecnológicas dos agentes privados. Como consequência, é de se presumir que não deve ter surtido efeito sobre a melhora da posição tecnológica e competitiva do Brasil diante de seus concorrentes no mercado internacional. Dessa forma, uma política de inovação, entendida como a principal orientação da política industrial, deve focalizar prioritariamente os determinantes das decisões empresariais de gastar em atividades inovativas (que determinam a demanda por incentivos públicos).

Almeida (2011) argumenta que, além da inovação, outra falha no desenho das políticas industriais, em especial no caso do PBM, é a falta de incentivos ao investimento privado e à exportação, ambos ligados, respectivamente, à manutenção da taxa de juros e da taxa de câmbio. De um modo geral, pode-se dizer que o foco anti-inflacionário dado pelo Regime de Metas trava o pleno desenvolvimento de quaisquer ambições de políticas industriais mais agudas. Essa ideia está presente também em Cano (2011), Sarti e Hiratuka (2011), entre outros.

Depois de colocados, ainda que de maneira superficial, os principais diagnósticos e críticas da literatura brasileira sobre o desenho e o desempenho das políticas industriais, uma conclusão se ressalta: o elemento ambiental está absolutamente ausente sob quaisquer perspectivas analíticas. A questão que permanece é: a falta de consideração pelo caráter ambiental das políticas industriais tem origem na escassez de elementos dessa categoria no bojo das mesmas, ou, na indiferença com que o tema é tratado por parte de seus analistas no Brasil? Acredita-se que a resposta para esse questionamento contempla ambas as conjecturas, como se buscará demonstrar nas seções seguintes.

Se por um lado alguns podem considerar este tipo de preocupação como algo estranho ao mote convencional da economia industrial, por outro, os esforços encontrados na literatura internacional mostram o oposto. Dito isso, vale um exame mais pormenorizado dos elementos que contenham alguma relação com questões ambientais dentro das três últimas políticas industriais brasileiras, ou da ausência dos mesmos.

\subsection{Política Industrial, Tecnológica e de Comércio Exterior - PITCE - (2003 - 2008)}

Em 26 de novembro de 2003, o Governo Federal lança o documento com as principais diretrizes da PITCE, a primeira política industrial em mais de duas décadas. Esse ponto deve ser considerado como uma das principais alterações no direcionamento da política econômica promovida já no primeiro mandato de Luiz Inácio Lula da Silva. Segundo Suzigan e Furtado (2006, p. 174):

O lançamento da PITCE em fins de 2003 representa, por si só, um fato positivo na medida em que demonstra ter sido superado o viés anti-PI14 que prevalecera por tanto tempo. E porque demonstra decisão política em favor de uma política industrial, ainda que sua formulação e implementação estejam longe de enfrentar o amplo leque de problemas impostos por uma estratégia de desenvolvimento centrada na indústria, impulsionada pela inovação e norteada por transformações tecnológicas

\footnotetext{
${ }^{14}$ Política industrial.
} 
e mudanças estruturais de empresas e indústrias, segundo o enfoque neoschumpeteriano/evolucionista.

Brasil (2003) mostra que as metas da PITCE dividiam-se em dois grandes grupos: as de curto prazo e as de médio e longo prazo. As de curto prazo se restringiam, resumidamente, à diminuição das restrições externas do País via ampliação do comércio internacional. Já as de médio e longo prazo incluíam o desenvolvimento das chamadas “atividades-chave”. É neste grupo que estão contidos os tímidos pontos de tangência da PITCE com aspectos ambientais:

\begin{abstract}
Promover a capacidade inovadora das empresas via concepção, projeto e desenvolvimento de produtos e processos. Estimular o incremento de atividades portadoras de futuro, como biotecnologia, software, eletrônica e optoeletrônica, novos materiais, nanotecnologias, energia renovável, biocombustíveis (álcool, biodiesel) e atividades derivadas do Protocolo de Kyoto ${ }^{15}$ (BRASIL, 2003, p. 10).
\end{abstract}

Deste pequeno transcrito alguns pontos devem ser estressados. Em primeiro lugar, o fato de energia renovável, biocombustíveis e atividades derivadas do protocolo de Kyoto estarem dentro das chamadas atividades "portadoras de futuro" demonstra que os formuladores da política reconheceram, até certo ponto, o fato de tais atividades fazerem parte do grupo de setores estratégicos para o desenvolvimento industrial brasileiro. No entanto, nada mais foi dito. Não foram especificadas quais as fontes de energia renovável tampouco quais os biocombustíveis que se intencionava promover, dando espaço à sobreposição e redundância. De acordo com o Balanço Energético Nacional de 2003, a matriz brasileira era composta por $41 \%$ de energia renovável, sendo que desse total, $14 \%$ era energia hidráulica e os 27\% restantes biomassa. Álcool e biodiesel são duas fontes energéticas biocombustíveis provenientes de biomassa e todas essas fontes energéticas discutidas poderiam ser contempladas como atividades presentes no debate promovido pelo Protocolo de Kyoto. Qual atividade seria priorizada? Todas ou alguma em particular? E de que forma isso ocorreria? Esses questionamentos que deveriam ter sido feitos à época não ocorreram deixando quase em branco o papel da PITCE na propulsão de alterações na matriz energética do País. Além disso, a menção ao Protocolo de Kyoto, quando vista em perspectiva, soa muito "protocolar”, uma vez que a redução de emissão de gases do efeito estufa era um assunto que estava na ordem do dia nos primeiros anos do século XXI.

\title{
3.2 Política de Desenvolvimento Produtivo - PDP - (2008 - 2011)
}

Lançada em maio de 2008, a Política de Desenvolvimento Produtivo (PDP) deve ser examinada em suas de três dimensões. A primeira é a de que esta é a política que deu continuidade aos esforços em políticas industriais iniciados com a PITCE. A segunda, muito importante, é entender que sua montagem e implantação foram concomitantes com a deflagração da crise internacional de 2008, o que deu à PDP um caráter profundamente anticíclico. Por fim, e em função da grande crise já citada, a PDP, funcionou como mais uma das frentes de medidas anticíclicas postas em prática pelo Governo Brasileiro e, dessa forma, disputou espaço com outras ações como, por exemplo, o Programa de Aceleração do Crescimento (PAC), o Programa Minha Casa Minha Vida, o Plano de Ação em Ciência, Tecnologia e Inovação (PACTI), entre outros.

Quando comparada com sua antecessora, além do enfoque maior no crescimento e dinamização da economia brasileira face à crise mundial, outro ponto de destaque é a maior escrutinização das metas e dos objetivos de cada instrumento. Essa característica, que por um

\footnotetext{
${ }^{15}$ O Protocolo de Kyoto é um tratado internacional, assinado por 83 Estados Nacionais em 11 de dezembro de 1997. O foco primário é a redução dos chamados gases do efeito estufa, em especial do dióxido de carbono $\left(\mathrm{CO}_{2}\right)$.
} 
lado facilita o trabalho de análise de resultados, por outro deixou claro que as preocupações ambientais passaram ao largo do considerado prioritário.

Das quatro macrometas, nenhuma possuía qualquer vínculo com setores, ou sequer com aspectos, ambientalmente relacionados. Nos chamados programas mobilizadores em áreas estratégicas estavam contidos medidas para fortalecimento da competitividade do País em quatro setores energéticos, sendo eles biodiesel, bioetanol, petróleo e gás natural e, por fim, energia nuclear. Nessas quatro áreas, as metas e desafios tinham relação com ampliação da produção, proteção e ênfase no conteúdo nacional, qualificação da mão de obra e desenvolvimentos de novas tecnologias. Pouquíssimo espaço foi dado a compromissos ambientais com exceção do vago desafio de "assegurar a sustentabilidade socioambiental" no caso do bioetanol e do biodiesel (MDIC, 2015).

\subsection{Plano Brasil Maior - PBM - (2011 - hoje)}

O PBM foi lançado no dia 02 de agosto de 2011 e sua lista de prioridades não se diferencia muito daquela apresentada pela PDP, ou seja, manter o crescimento econômico inclusivo e ajudar no combate aos efeitos da crise internacional. Ocioso lembrar que não eram esperadas as pesadas crises político-institucional e econômica que vêm matando o dinamismo da economia brasileira, desde meados de 2014. Neste cenário lúgubre, onde a mentalidade do ajuste fiscal impera, os efeitos negativos sobre a envergadura e efetividade de políticas desse tipo, são notórios.

A estruturação do PBM compreende duas dimensões para orientação da política sendo uma setorial e outra sistêmica. Na dimensão setorial existem cinco diretrizes, sendo que, do ponto de vista econômico-ambiental, uma delas se sobressai. De acordo com a página oficial do Plano, no site do Ministério do Desenvolvimento, Indústria e Comércio (MDIC), a Diretriz Estruturante de número três prevê o desenvolvimento das cadeias de suprimento em energias, sendo elas petróleo, gás e energias renováveis, como etanol, eólica, carvão vegetal e solar. Na dimensão sistêmica, por sua vez, destaca-se o item designado como produção sustentável. Sobre esta estão anunciadas medidas nas seguintes áreas:

Ecodesign, em busca de melhorias de produtos e processos para a produção mais limpa; construção modular para a redução de resíduos em obras de construção civil; definição de critérios de sustentabilidade para edificações; apoio ao desenvolvimento de cadeias de reciclagem (em consonância com a Política Nacional de Resíduos Sólidos); desenvolvimento regional sustentável a partir de competências e recursos disponíveis localmente; e estímulos ao desenvolvimento e à adoção de fontes renováveis de energia pela indústria (em consonância com a Política Nacional de Mudança do Clima e com a Política Nacional de Energia) (MDIC, 2015).

Interessante sublinhar que tais medidas, tanto na dimensão setorial quanto na dimensão sistêmica ou não possuem metas estipuladas ou estas não são individualizadas. A única exceção que se sobressai é o caso da energia uma vez que, das dez metas anunciadas para o Plano todo, duas têm relação com este setor. Uma delas prevê a "elevação da participação nacional no mercado de tecnologias, bens e serviços ligados à energia (valor de transformação industrial/valor bruto da produção - VTI/VBP)" ${ }^{16}$ de 64\% para 66\% (MDIC, 2015). Dois pontos devem ser levados em consideração. O primeiro deles é a ausência de data-limite para alcançar a nova marca pretendida. Em segundo lugar, vale notar que não

${ }^{16} \mathrm{O}$ índice VTI/VBP funciona como uma medida de densidade de produção industrial, comparando o valor adicionado da produção a tudo aquilo que foi produzido em território brasileiro. Quanto maior o índice, ou quanto mais próximo de 100\%, mais “nacionalizada” é a produção, neste caso, de energia. 
existe distinção sobre qual o tipo de energia que está contemplada nesse objetivo. Pelo fato da matriz energética brasileira ser uma das mais limpas do mundo, um examinador poderia supor que dentro deste esforço de ampliação da densidade do setor energético estariam contempladas algumas fontes renováveis, como por exemplo, a energia hidroelétrica e o etanol, sendo dessa forma, uma medida condizente com as crescentes preocupações ambientais. No entanto, a emergência da camada do pré-sal, em fins de 2007, marcou o início de uma mudança profunda no foco das atenções do Estado Brasileiro, naquilo que diz respeito ao setor energético, em direção a uma política muito mais aguda para a exploração petrolífera. Em outras palavras, não se sabe exatamente qual o setor, ou os setores, que se pretendeu considerar neste caso, contudo, existe uma tendência clara de direcionamento para o setor petrolífero.

Outra meta importante, dessa fez com preocupação mais evidenciada para com o problema ambiental, prevê a produção mais limpa, através da diminuição do consumo de energia por unidade do PIB industrial, de 150,7 tep ${ }^{17} / \mathrm{R}$ \$ milhão, em 2010, para 137 tep/R\$ milhão, sem data-limite. Esse esforço de redução de aproximadamente $9 \%$ do consumo por unidade do PIB se encaixa no chamado decoupling ou desacoplamento, já discutido anteriormente.

Utilizando a medida inversa, US\$/kg de petróleo, é possível comparar o posicionamento do Brasil perante alguns outros países no que diz respeito ao consumo de energia não só para o setor industrial, mas para a economia como um todo.

\section{Gráfico 2: Uso de US\$/kg de petróleo na economia}

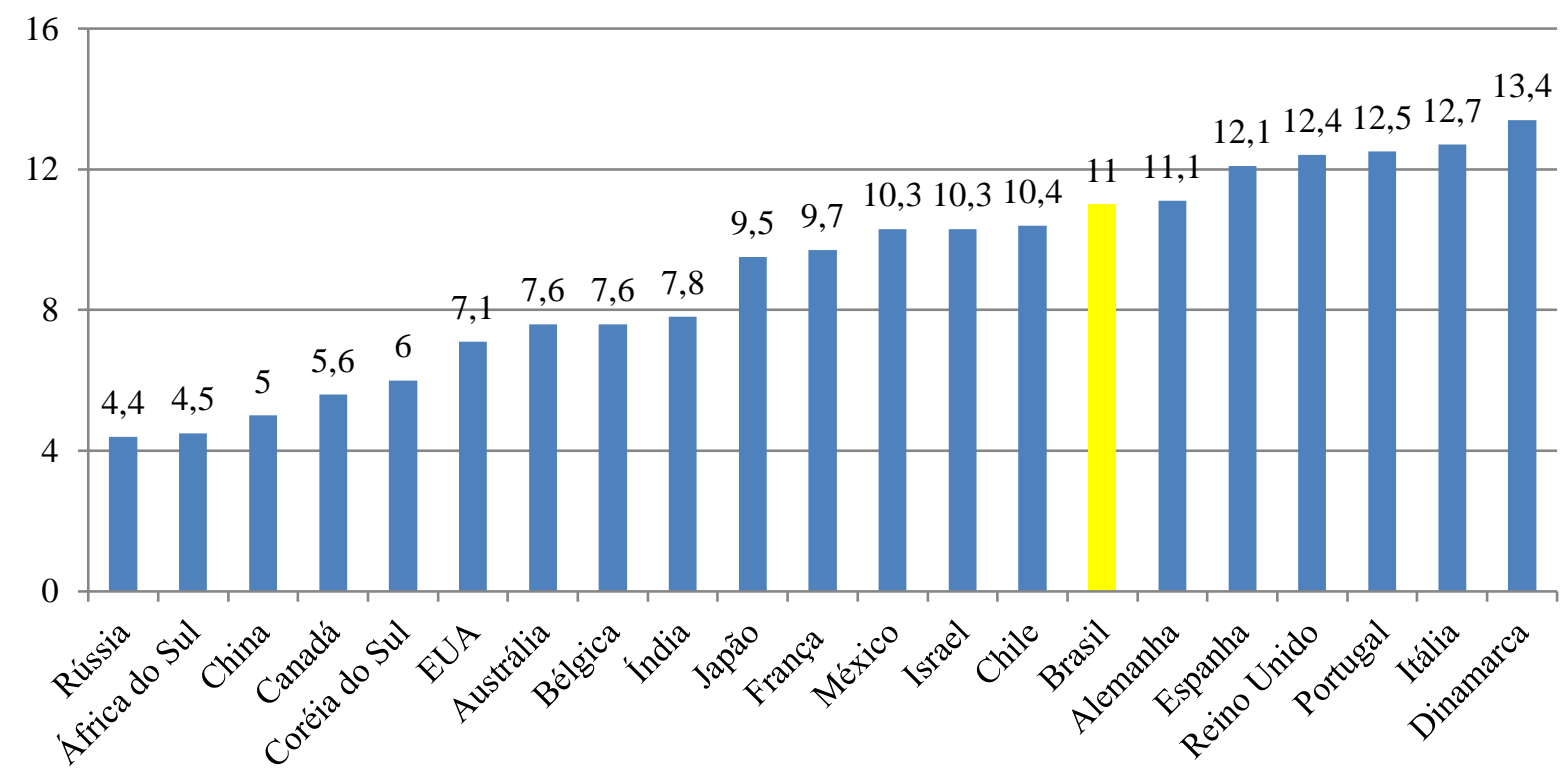

Elaboração própria a partir de dados do Banco Mundial (2015).

O gráfico 1 mostra que o posicionamento brasileiro, em 2011, era consideravelmente favorável, colocando o Brasil ao lado de países desenvolvidos como a Alemanha, por exemplo. Mais do que isso, o gráfico 1 também mostra que outros países em

\footnotetext{
17 TEP - Toneladas equivalentes em petróleo. É uma medida energética que torna possível a conversão de qualquer fonte de energia em produção de termos equivalentes em petróleo. Por exemplo, de acordo com a Agência Internacional de Energia (IEA), uma tonelada equivalente em petróleo se iguala a 11,63 MWh.
} 
desenvolvimento, em especial os que formam o BRICS (Rússia, Índia, China e África do Sul), estão bem atrás do Brasil quando o assunto é consumo de energia por unidade do PIB.

Ao olhar o problema sob essa perspectiva, o esforço de redução da quantidade de TEP's por R 1 se mostra como a principal medida já tomada nas três políticas industriais analisadas. Entretanto, a não estipulação de data-limite para cumprimento da meta dificulta a análise da sua efetividade.

\section{Conclusão}

De acordo com a Organização das Nações Unidas para o Desenvolvimento Industrial “a nenhum país pode ser negado seu potencial em participar da próxima revolução industrial e a próxima revolução industrial certamente será verde"18 (ONUDI, 2011, p. 3). Apesar de nem sempre explícita, essa é a convicção que circunscreve a maioria dos autores preocupados com a política industrial verde em âmbito internacional. Trata-se, na verdade, de buscar uma melhor adequação das economias, em especial daquelas em desenvolvimento, às dificuldades impostas pelas restrições ambientais. De certa forma, a seleção da literatura internacional exposta na seção 2 pode ser compreendida como um conjunto de estruturas fundamentais para a montagem de uma política industrial verde consciente deste cenário. Ao passo em que já foram identificados os esforços, ainda que limitados, das três últimas políticas industriais brasileiras dentro da questão ambiental, já é possível executar uma espécie de contraste o entre o que foi feito no Brasil e o que estaria mais próximo do ideal.

A principal prioridade da política industrial, no Brasil, ainda é ampliar a escala e o volume de produção, recuperar e proteger alguns elos da cadeira produtiva em setores específicos e, de forma ainda primária, criar um ambiente propício à pesquisa e desenvolvimento e à inovação (CANO, 2011; SARTI; HIRATUKA, 2015). No entanto, é até certo ponto fácil defender que a questão ambiental está na ordem do dia e deve ser considerada na montagem de tais políticas.

Considerando-se os chamados esforços "verdes”, o setor de energias renováveis foi o mais agraciado pelas medidas da PITCE, da PDP e do PBM. Contraditoriamente, esse setor é concorrente direto da maior fonte de dinamismo da economia nacional na última década, a cadeia do petróleo. Essa limitação na envergadura das políticas industriais brasileiras é um indicativo de que, no médio prazo, não há intenção de alterações mais profundas no modelo da matriz energética nacional. Apesar disso, o Brasil ainda é referência internacional quando o assunto é biocombustíveis e energia hidroelétrica, ambas fontes energéticas com grandes oportunidades de desenvolvimento.

Para além do setor energético, pouco foi feito para o esforço de integração de propósitos ambientais à política industrial. A conduta brasileira, em função de sua dimensão econômica, dotação de recursos naturais e inserção no comércio internacional, necessita ser mais aguda no que diz respeito à transição para uma economia verde. Para tanto, quatro pontos se destacam.

Em primeiro lugar, de acordo com o defendido por Dutz e Sharma (2012), é preciso reformar as bases da educação nos países em desenvolvimento para se conseguir instaurar um ambiente propício para o pleno funcionamento de políticas industriais verdes. O Brasil tem setores com capacidade tecnológica suficiente para implantação de tais políticas. No entanto, o abismo educacional existente no País é um grande obstáculo a ser superado. Os esforços

18 Tradução nossa. 
recentes em ampliar o acesso ao ensino superior, apesar de necessários, não são suficientes. É preciso também incluir na agenda de reformas, os ensinos fundamental e médio. O intuito aqui não é apenas melhorar a qualificação da mão de obra, mas, também, o de criar um mercado interno cada vez mais consciente da importância de se promover a transição rumo ao desenvolvimento sustentável.

Em relação à montagem da política industrial, propriamente dita, muito se discute atualmente sobre seus instrumentos de financiamento. O BNDES e a Financiadora de Estudos e Projetos (FINEP) são exemplos muito citados quando se discute fomento à inovação. Seria muito relevante canalizar parte desses esforços na promoção de um ambiente inovativo mais propício ao surgimento de novos bens, serviços e tecnologias verdes. Parte desse suporte também deve dar conta de reduzir uma parcela dos riscos envolvidos nos trâmites desse mercado relativamente novo, como alertam Criscuolo e Menon (2014).

No que diz respeito ao comércio internacional, qualquer análise breve da balança comercial brasileira é capaz de revelar a pesada influência das chamadas commodities minerais e agrícolas dentro da pauta exportadora nacional.

\section{Tabela 1: Commodities minerais e agrícolas na balança comercial brasileira}

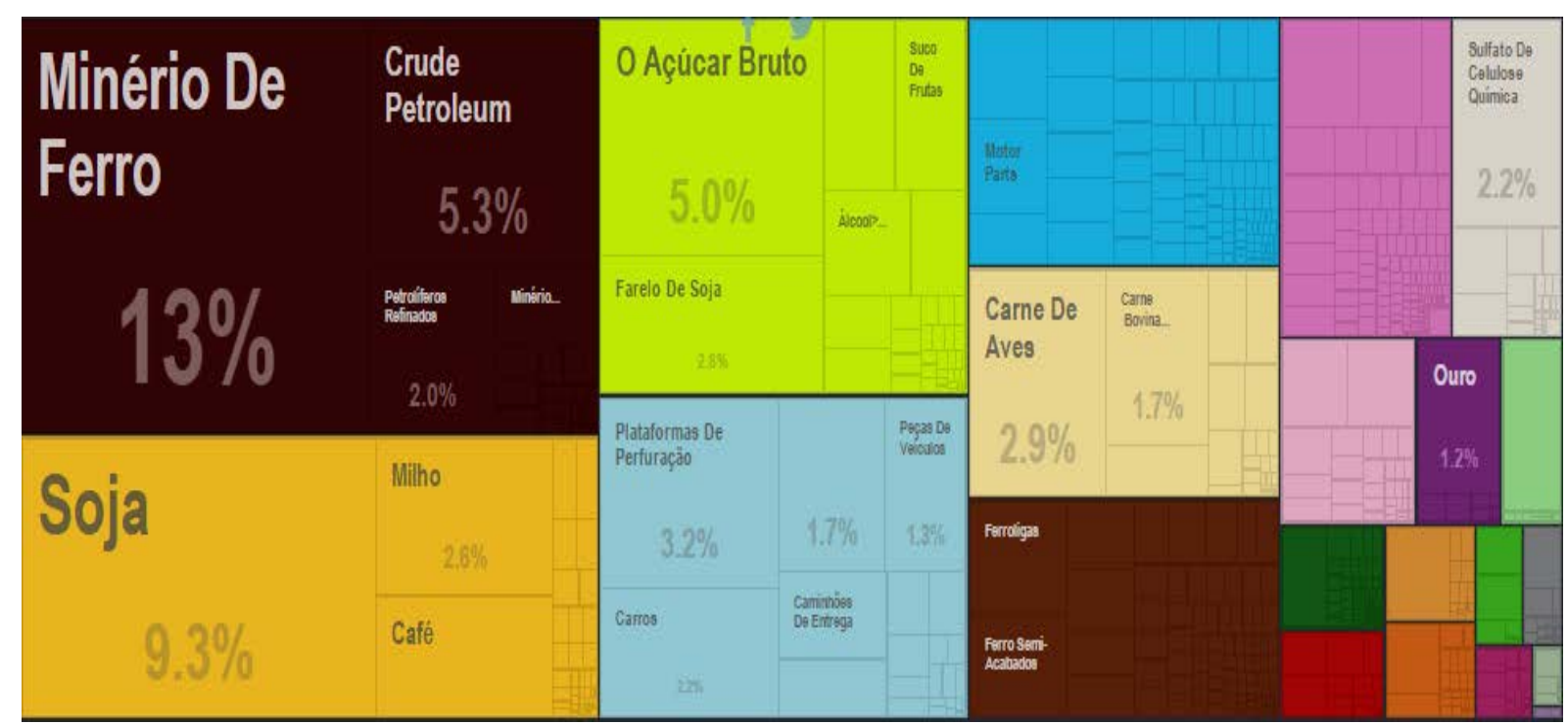

Elaboração e dados retirados do The Observatory of Economic Complexity (2015)

Vale salientar o alerta de Altenburg (2011) a respeito do crescente nível de rigor e exigências de boa parte dos países importadores com relação aos métodos de produção de tais bens e materiais. Além, é claro, da necessidade de criação de um processo sustentável para continuidade dessas atividades, tanto do ponto de vista econômico como do ponto de vista ambiental.

Por fim, outra característica pouco aproveitada, dentro do âmbito de uma política industrial verde, de acordo com Schwarzer (2013), é a utilização dos instrumentos fiscais de tributação. Se bem desenhada, a política tributária pode 1) elevar o dinamismo de setores verdes (ou, do contrário, prejudicar relativamente o dinamismo daqueles setores menos eficientes do ponto de vista ambiental). Um exemplo claro, neste caso, é o que houve com a redução da tributação (IPI, Pis/Pasesp e Cofins) do setor de painéis solares. A mesma lógica pode ser aplicada a diversos setores podendo servir, em alguns casos, como estratégia para obter novos recursos fiscais. 
Sabe-se que a crise atual possui várias origens e, portanto, sua superação requer empenho nas mais variadas áreas. Este trabalho serve para indicar que uma das saídas para a crise pode estar, justamente, no investimento e no desenvolvimento de uma economia mais verde, com grandes oportunidades que já estão sendo aproveitadas por outras grandes nações do mundo, tanto ricas quanto pobres.

\section{Referências}

ALMEIDA, Mansueto de. Padrões de política industrial: a velha, a nova e a brasileira. In: BACHA, Edmar; BOLLE, Monica Baumgarten de (Org.). O Futuro da Indústria no Brasil: desindustrialização em debate. Rio de Janeiro: Civilização Brasileira, 2013. Cap. 11. Versão Draft.

ALMEIDA, L. T. de. Green Economy: Reinforcing ideas, hoping for actions. Estudos Avançados 26 (74), 2012.

ALTENBURG, Tilman. Industrial Policy in Developing Countries: Bonn: Deutsches Institut Für Entwicklungspolitik, 2011. 110 p. (Discussion Papers). Disponível em: <https://www.diegdi.de/uploads/media/DP_4.2011.pdf>. Acesso em: 08 dez. 2015.

BRASIL. Diretrizes de Política Industrial, Tecnológica e de Comércio Exterior. Brasília: Governo Federal, 2003. 22 p. Disponível em: <www.anped11.uerj.br/diretrizes.pdf>. Acesso em: 12 nov. 2013.

BRASIL. MINISTÉRIO DAS MINAS E ENERGIA. . Balanço Energético Nacional 2003. Brasília, Governo Federal: 2004. Disponível em: <https://ben.epe.gov.br>. Acesso em: 12 jan. 2016

CANÊDO-PINHEIRO, Mauricio et al. Por que o Brasil não Precisa de Política Industrial. Ensaios Econômicos, Rio de Janeiro, n. 644, p.1-39, mar. 2007. Disponível em: <http://www.fgv.br/professor/ferreira/PI2007.pdf>. Acesso em: 14 ago. 2015.

CANO, Wilson; SILVA, Ana Lucia Gonçalves da. Política Industrial do Governo Lula. Campinas: IE/UNICAMP, 2010. (Texto para Discussão $\mathrm{n}^{\circ} 181$ ). Disponível em: $<$ http://horia.com.br/sites/default/files/documentos/texto181_politica_industrial.pdf $>$. Acesso em: 22 jul. 2012.

COSBEY, Aaron. Green Industrial Policy and the World Trading System. Estocolmo: Entwined, 2013. (Green Industrial Policy and the World Trading System). Disponível em: $<$ http://www.iisd.org/pdf/2013/entwined_brief_green_industrial.pdf $>$. Acesso em: 11 dez. 2015

CRISCUOLO, Chiara; MENON, Carlo. Environmental Policies and Risk Finance in the Green Sector. OCDE Science, Technology And Industry Working Papers, Paris, 42 p., jan. 2014. Disponível em: <http://dx.doi.org/10.1787/5jz6wn918j37-en>. Acesso em: 05 jan. 2016.

D'AVIGNON, Alexandre; CARUSO, Luiz Antônio Cruz. O caráter necessariamente sistêmico da transição rumo à economia verde. Política ambiental. Economia Verde: desafios e oportunidades, Belo horizonte, n.8, p.24-41, jun. 2011. 
DALY, H. E. From a failed growth economy to steady-state economy. In: Encyclopedia of Earth. Cutler J (Ed). Cleveland (Washington, D.C.: Environmental Information Coalition, National Council for Science and the Environment), 2009.

DREXHAGE, John; MURPHY, Deborah. Sustainable Development: from Brundtland to Rio 2012. Nova Iorque: ONU, 2010. 26 p. (Background Paper* prepared for consideration by the High Level Panel on Global Sustainability at its first meeting.)

DUTZ, Mark A.; SHARMA, Siddharth. Green Growth, Technology and Innovation. The World Bank, 2012. 47 p. (Policy Research Working Paper). Disponível em: <ssrn.com/abstract=1980586>. Acesso em: 13 dez. 2015.

GANESAN, Karthik et al. Assessing Green Industrial Policy: International Institute For Sustainable Development, 2014. 111 p. Disponível em: <https://www.iisd.org/gsi/sites/default/files/rens_gip_india.pdf>. Acesso em: 04 jan. 2015.

GEORGESCU-ROEGEN, Nicholas. Energy and Economic Myths. Southern Economic Journal, v. 41, n. 3, p.1-24, 1973.

GROSSMAN, Gene M.; KRUEGER, Alan B.. Economic Growth and the Environment. The Quarterly Journal Of Economics, v. 110, n. 2, p.353-377, maio 1995. Trimestral.

HALLEGATTE, Stéphane; FAY, Marianne; VOGT-SCHILB, Adrien. Green Industrial Policies: The World Bank, 2013. 27 p. (Policy Research Working Paper). Disponível em: <ssrn.com/abstract=2346540>. Acesso em: 04 jan. 2016

KARP, Larry; STEVENSON, Megan. Green Industrial Policy: trade and theory. Berkeley. 2012. $41 \quad$ p. Disponível em: $<$ http://are.berkeley.edu/ karp/GreenPolicyWB_January_2012_Karp_Stevenson.pdf>. Acesso em: 10 dez. 2016.

LÜTKENHORST, Wilfried; PEGELS, Anna. Germany's Green Industrial Policy Stable Policies - Turbulent Markets: The costs and benefits of promoting solar PV and wind energy. International Institute For Sustainable Development, 2014. Disponível em: $<$ https://www.iisd.org/gsi/sites/default/files/rens_gip_germany.pdf>. Acesso em: 04 jan. 2016.

MARTINEZ-FERNANDEZ, Cristina et al. Improving the Effectiveness of Green Local Development: Paris: OCDE, 2013. 61 p. (OECD Green Growth Papers). Disponível em: $<$ http://www.oecd-ilibrary.org/environment-and-sustainable-development/improving-theeffectiveness-of-green-local-development_5k3w6ljtrj0q-en>. Acesso em: 18 dez. 2015.

MELO, Tatiana M.; FUCIDJI, José R.; POSSAS, Mário L.. Política industrial como política de inovação: notas sobre hiato tecnológico, políticas, recursos e atividades inovativas no Brasil. Revista Brasileira de Inovação, Campinas, v. 14, n. especial , p.11-36, jul. 2015. Disponível em: <http://ocs.ige.unicamp.br/ojs/rbi/article/view/1146/757>. Acesso em: 13 set. 2015.

PEGELS, Anna. Why we need a green industrial policy. In: PEGELS, Anna (Org.). Green industrial policy in emerging countries. Londres: Routledge, 2013. Cap. 1, p. 11. Disponível em: <http://papers.ssm.com/sol3/papers.cfm?abstract_id=2334309>. Acesso em: 20 dez. 2015. 
REZENDE, Leonardo. Politica industrial para inovacao: uma analise das escolhas setoriais recentes. In: BACHA, Edmar; BOLLE, Monica Baumgarten de (Org.). O Futuro da Indústria no Brasil: desindustrialização em debate. Rio de Janeiro: Civilização Brasileira, 2013. Cap. 11. Versão Draft.

RODRIK, Dani. Green Industrial Policy. Oxford Review Of Economic Policy, Oxford, v. 30, n. 3, p.469-491, 2014. Trimestral. Disponível em: $<$ https://www.sss.ias.edu/files/pdfs/Rodrik/Research/Green-growth-and-industrialpolicy.pdf $>$. Acesso em: 28 nov. 2015.

SARTI, Fernando; HIRATUKA, Célio. Desenvolvimento industrial no Brasil: oportunidades e desafios futuros. Campinas: IE/UNICAMP, 2011. 40 p. (Texto para Discussão $\quad \mathrm{n}^{0}$ 187). Disponível em: <www.eco.unicamp.br/docprod/downarq.php?id=1817\&tp=a>. Acesso em: 09 nov. 2015.

SCHWARZER, Johannes. Industrial Policy for a Green Economy. International Institute For Sustainable Development, 2013. 68 p. Disponível em: <http://www.iisd.org/pdf/2013/industrial_policy_green_economy.pdf>. Acesso em: 10 dez. 2015.

SOLOW, Robert. The Economics of Resources or the Resources of Economics. American Economic Review, v. 64, n. 2, p.1-14, maio 1974. Papers and Proceedings of the Eighty-sixth Annual Meeting of the American Economic Association.

SUZIGAN, Wilson; FURTADO, João. Política Industrial e Desenvolvimento. Revista de Economia Política, São Paulo, v. 26, n. 2, p.163-185, abr./jun. 2006. Trimestral. Disponível em: <http://www.scielo.br/scielo.php?script=sci_arttext\&pid=S0101-31572006000200001>. Acesso em: 24 ago. 2014

UNEP. China's Long Green March. Nairobi: 2013. 36 p. (United Nations Environment Programme). Disponível em: <http://www.unep.org/greeneconomy/Portals/88/Research Products/China synthesis report_FINAL_low res_22nov.pdf>. Acesso em: 04 jan. 2016.

UNEP. Decoupling natural resource use and environmental impacts from economic growth. Nairobi. 2011174 p. (United Nations Environment Programme).

UNIDO (Áustria). Policies for supporting Green Industry. Viena: United Nations Industrial Development Organization, 2011. 88 p. (UNIDO Green Industry).

WU, Mark; SALZMAN, James. The Next Generation of Trade and Environment Conflicts: The Rise of Green Industrial Policy. Northwestern University Law Review. v. 108, n. 2, p.401-474, 2014.2 Disponível em: $<$ http://scholarlycommons.law.northwestern.edu/cgi/viewcontent.cgi?article=1022\&context=n ulr>. Acesso em: 15 dez. 2015. 